\title{
An Agent-Based Model of Residential Energy Efficiency Adoption
}

\author{
Magnus Moglia', Aneta Podkalicka², James McGregor ${ }^{3}$ \\ ${ }^{1}$ CSIRO Land and Water, Ian Wark Building (B203), Clayton South VIC 3169, Australia \\ ${ }^{2}$ School of Media, Film and Journalism, Monash University, Caulfield Campus, 900 Dandenong Rd., Caulfield \\ East VIC 3145, Australia \\ ${ }^{3}$ Blue Tribe Co., Newcastle NSW 2300 Australia \\ Correspondence should be addressed tomagnus.moglia@csiro.au \\ Journal of Artificial Societies and Social Simulation 21(3) 3, 2018 \\ Doi: 10.18564/jasss.3729 Url: http://jasss.soc.surrey.ac.uk/21/3/3.html \\ Received: 03-01-2018 Accepted: 28-03-2018 Published: 30-06-2018
}

\begin{abstract}
This paper reports on an Agent-Based Model. The purpose of developing this model is to describe 'the uptake of low carbon and energy efficient technologies and practices by households and under different interventions'. There is a particular focus on modelling non-financial incentives as well as the influence of social networks as well as the decision making by multiple types of agents in interaction, i.e. recommending agents and sales agents, not just households. The decision making model for householder agents is inspired by the Consumat approach, as well as some of those recently applied to electric vehicles. A feature that differentiates this model is that it also represents information agents that provide recommendations and sales agents that proactively sell energy efficient products. By applying the model to a number of scenarios with policies aimed at increasing the adoption of solar hot water systems, a range of questions are explored, including whether it is more effective to incentivise sales agents to promote solar hot water systems, or whether it is more effective to provide a subsidy directly to households; or in fact whether it is better to work with plumbers so that they can promote these systems. The resultant model should be viewed as a conceptual structure with a theoretical and empirical grounding, but which requires further data collection for rigorous analysis of policy options.
\end{abstract}

Keywords: Energy Efficiency, Policy Assessment, Innovation Diffusion, Solar Hot Water, Consumat, Ex-Ante

\section{Introduction}

1.1 This paper describes the Nudge-Emergence-Diversity (NED) model, an Agent-Based Model (ABM) that represents the adoption of energy efficient technology and behaviours within a diverse population, and incorporates: behaviour-driven models of decision making; diversity of the population through rich survey datasets of shifting preferences; and the emergence of behaviours within social systems, including representation of trust-based information networks and influence across social networks.

1.2 This model is in line with recent papers arguing that ABM is a very promising approach for helping to build better theories and models of energy demand and the adoption of energy efficient technology (Rai \& Henry 2016). It is also in line with the thinking of recent Nobel Prize laureate Richard Thaler and his colleagues who argue that governments can benefit significantly from investing in behaviourally informed policies to nudge community behaviour in cost-effective manners, using energy efficiency as one of the success stories in this context Benartzi et al. 2017).

1.3 The case for reducing household energy use is related to the notion that there are profound impacts from human activity on the planet, which some argue is pushing the planet into a new geological era, the Anthropocene Zalasiewicz et al. 2010. These are profound changes on the functioning of the planet and from a human perspective, the earth is now outside of its safe operating space, in at least three areas of which one is relating to climate change (Rockström et al.2009). Among the diverse impacts of climate change, including ecosystem and species loss (Thuiller et al. 2005) Brook \& Barnosky|2013), from a human perspective perhaps the most worrying concern is that without staying within the safe operating space, including on climate change, it looks difficult for global food systems to meet food demand on current projections (Conijn et al. 2018). This shows that it is 
imperative to reduce global greenhouse gas emissions. The residential sector accounts for approximately $30 \%$ of worldwide energy use Swan \& Ugursal 2009) and the energy sector is the largest contributor to greenhouse gas emissions in most countries (Höhne et al. 2011).

1.4 There are two main approaches to reducing the Carbon Dioxide equivalent $\left(\mathrm{CO}_{2}-e\right)$ emissions from the residential sector, namely through reducing household energy use (increased energy efficiency) or the adoption of renewable energy technologies. Increasing the energy efficiency of households typically requires both behaviour change and technology change. Residential adoption of more energy efficient technology or change of consumer behaviour is an important strategy for mitigating climate change. This is in the context that humaninduced $\mathrm{CO}_{2}-e$ emissions from residential energy use have been estimated to represent $11 \%$ of total $\mathrm{CO}_{2}-e$ emissions in the European Union (Drummond \& Ekins 2016), and 21\% of $\mathrm{CO}_{2}-e$ emissions in the United States Estiri 2015. In a status quo scenario with a projected growing population, Australia's $\mathrm{CO}_{2}-e$ emissions from residential energy use are expected to grow by $38 \%$ by 2050 (Hetherington et al. 2015). In fact, it has been found that without energy efficiency improvements in the past, over a 30 year time period the Organisation for Economic Cooperation and Development (OECD) nations would cumulatively have used 49\% more energy than they used as of 1998 (Geller et al.2006).

1.5 Energy efficiency in households particularly relates to lighting and appliances, refrigeration and Heating, Ventilation, and Air-Conditioning as well as water heating. It has been estimated that in Australia, the following was a breakdown of residential overall residential energy use: Heating, Ventilation, and Air-Conditioning 40\%, water heating $21 \%$, lighting $6 \%$ and appliances including for refrigeration and cooking 33\% Australian Government 2013. In many countries, there are policies in place to promote the uptake of energy efficient technologies. For example, the OECD recommends raising awareness of energy efficient technology, and education of the public about the need for environmental action. The OECD also recommends grants and subsidies focusing on low-income households (OECD 2014). But the question is, what works when promoting the adoption of energy efficient technology and what doesn't work. Ultimately, the adoption of energy efficient technology by households involves individual consumer choices; a process subject to a complex sets of factors and relationships that is not well-represented by the rational choice model of human behaviour whereby which a person weighs up benefits and costs of different options and maximises utility (Frederiks et al.2015). To be precise, this type of consumer choice is subject to the usual behavioural tendencies, such as being swayed by social comparisons, being loss and risk-averse, tending to favour status quo over change, and wanting to achieve a smaller set of goals rather than evaluating options more holistically (Frederiks et al.2015). Furthermore, it has been found that the preferences can vary considerably in a population and that the types of criteria adopted depend strongly on the type of technology that is chosen; for example, thermal comfort is the most important factor for Heating, Ventilation, and Air-Conditioning systems, but the light quality is the most important factor for lighting. In fact, this highlights an important aspect of consumer choice here: energy efficiency or even financial aspects are often mere secondary factors.

1.6 There is extensive research on the factors that household decision makers consider when they make decisions whether or not to adopt energy efficient technologies in their homes. For example, when households consider purchasing Light-Emitting Diode (LED) lighting, they may consider the level of illumination and the ability to render colours naturally, the expected life of a bulb, the toxicity of materials, the total harmonic distortion (a technical term relating to electricity supply), the temperature emitted from the bulb and the overall environmental impacts of the lighting technology (Aman et al. 2013, Di Maria et al. 2010; Khan \& Abas 2011; Hicks $\&$ Theis 2014). When households consider the purchase of an Heating, Ventilation, and Air-Conditioning system, they may consider the level of improvement in thermal comfort, the level of inconvenience of making the change, the expected increase in the resale value of the property, any disturbing noise from the system, or any financial issues such as split incentives (Noonan et al. 2013, Wilson et al.2015, Chua et al. 2013). There are also behavioural tendencies influencing the adoption of technology (Frederiks et al. 2015), such as the free-riding effect (trying to gain benefits without paying), variable trust in information sources (seeking judgments from trusted sources), and availability bias (drawing on knowledge or information that is easily available). Furthermore, how decision maker(s) in a particular household make their choice is highly variable depending on the particular preferences. Thus, the process of adopting technology ought to be modelled in a way that considers diversity in the population, social influence, influence from information flows, and ultimately how these factors play out at an individual decision maker scale, but create emergent outcomes at an aggregate scale, and ABM provides such a modelling framework (Rai \& Henry 2016).

1.7 The ABM described in this paper has been named NED after these functions, i.e. N for "Nudging" to reflect the representation of behavioural science, E for "Emergence" to reflect the representation of aggregate outcomes from a complex ecosystem of agents, and D for "Diversity" to reflect the representation of a diverse community.

1.8 In this paper, the justification, design, implementation and application of the NED model are described. First 
the context of the study will be explained, then other similar ABMs are reviewed, subsequently, a description and justification of the model will be described, and then its application will be showcased in one case, followed by a discussion about how to use the model, limitations, and potential for improvements.

\section{The Use of ABM to Describe Innovation Diffusion}

2.1 Innovation diffusion modelling, first introduced by Rogers (1962), is a field of research which arose out of the analogy between the physical process of particle intermingling thereby allowing heat transfer, and the sociotechnical process by which technology is dispersed through a population of humans, with a particular focus on the role of communication. For years, innovation diffusion modelling was based on the use of equations, such as the epidemic model (Gupta \& Jain 2012), the logistic model (Gruber \& Verboven 2001), or the Bass diffusion model (Bass 1969,2004). Equation-based models have some limitations, however, as was observed and noted for example by Higgins and colleagues 2011; 2014. Even with highly refined equations based models, whilst very useful and pushing the boundaries of what is possible, it still struggles to adequately represent complex decision rules, full heterogeneity in actor attributes, the role of multiple actors types and social networks Higgins et al.2012). Faced with these limitations, Moglia and colleagues reviewed alternatives for overcoming them and identified that $A B M$ with a socio-psychological foundation is a viable alternative (2017). Furthermore it can be argued that $A B M$ has the same limitations of all models because prediction is always conditional, i.e. subject to the conditions set out in the model Boschetti et al. 2011). Therefore, it is suggested that ABM is explored as an alternative to equation-based diffusion modelling of technology diffusion processes in particular in order to support ex-ante policy assessment in areas such as when wanting to promote energy efficient technology.

2.2 ABM is a type of computational model used for simulation and which emerged out of the research fields of Artificial Intelligence and Cellular Automatons. ABM allows for software representation of agents' dynamic behaviours and decision making in interaction with each other and with their environment Gilbert \& Troitzsch 2000, Perez \& Batten 2006). ABM has been used in a diverse number of topics, including archaeology, biological sciences, economics, ecology, electricity market analysis, financial analysis, social science, transport systems and water management, among others (Macal 2016; Macal \& North 2005; Moglia et al. 2010). More recently, ABMs have been proposed as a particularly suitable alternative for describing innovation diffusion processes in the energy and resource efficiency context (Rai \& Henry|2016:| Moglia et al.|2017).

2.3 The modelling of innovation diffusion using ABM is growing in maturity, as indicated by the review by Kiesling et al. (2012). In addition, it is noted that if calibrated and when compared to a more standard approach for describing innovation diffusion, i.e. equation-based models, ABM has similar predictive capacity (Mao et al. 2015) but greater flexibility in the ex-ante assessment of policy options as illustrated by Sopha and colleagues 2017. Examples of existing ABMs applied to the energy efficiency context are explorations of the adoption of hybrid electric vehicles (Tran 2012); alternative fuel vehicles (Zhang et al.2011); biomass fuels (Günther et al. 2011); wood pellet heating systems (Sopha et al.|2013); natural gas vehicles (Sopha et al.|2017); alternative fuels (Van Vliet et al.2010); and commercial buildings retrofits (Marquez et al.2013).

2.4 The models by Sopha and colleagues 2013 are particularly promising as they consider an advanced sociopsychological model of household decision making based on the Consumat theory, yet they also lack the wider range of agents that contribute to the adoption process, i.e. information or sales agents. Our model is similar to that by Sopha et al. but slightly adjusts the Consumat decision-making algorithm and also introduces actions by sales agents and information agents.

2.5 Another related model, the Community Energy Demand Social Simulator (CEDSS), was developed by Gotts \& Polhill 2017) with very similar aims to the NED model. The household decision making in CEDSS is based on goal-framing theory where householders focus either on hedonic, egoistic or biospheric goals and explore the full market of products rather than individual products separately. CEDSS focuses primarily on describing householder decision making and not so much on additional agent types. It has also been shown that the way that the goal-framing theory is deployed can lead to significantly different implementation and results, as described by Polhill \& Gotts 2017). This raises concerns about the application of ABM and highlights the need to be careful in the specification of decision-making models.

\section{The Agent-Based Model}

3.1 This section describes the model using the Overview-Design concepts-Details (ODD) protocol which has been proposed as a standardised protocol for reporting ABMs (Grimm et al. 2006, 2010). 


\section{Purpose}

3.2 The purpose of developing this model is to describe 'the uptake of low carbon and energy efficient technologies and practices by households and under different interventions'. There is a particular focus on modelling nonfinancial incentives as well as the influence of social networks and the decision making by multiple types of agents in interaction, not just households.

\section{Implementation}

3.3 The model has been implemented in NetLogo 5.3.1 (Wilensky|1999).

3.4 To promote usability, the principle for the model is to allow the user as much flexibility as possible in exploring assumptions and sensitivity to model parameters through the user interface.

3.5 The modelling has been informed through a co-design process whereby we have involved the potential users of the model as collaborators in the research project. The potential users we have involved are at the Office of Environment and Heritage which is part of the New South Wales (NSW) State Government

3.6 The model co-design was carried out by embedding collaborators in ongoing project team meetings, involving other collaborators in regular discussions about iterations of the model with presentations and feedback sessions. The co-design can best be described as group model building, as described by Hovmand (2013). Vennix (1996) specifies four distinguishing factors of group modelling and our approach is based on:

- Firstly, the core issue was specified based on learning from previous efforts at building innovation diffusion models to address a known user need. In previous studies with the collaborators, innovation diffusion models were based on equation-based approaches (Higgins et al.,2011, 2014).

- Secondly, an unstructured group process was adopted based on regular team meetings and ongoing conversations about data and assumptions. This was supported by collaborators having good working knowledge of ABM based on previous studies and their own research.

- Thirdly, the process was first focused on the informal causal map to generate a shared understanding, which eventually allowed the team to move towards a formal computer simulation model. This learning process was based on iterations of presentations and feedback sessions.

- Fourthly, the team started with a relatively blank slate with no preconceived model. However, the approach was informed by previous modelling efforts, and quite quickly the team settled on the Consumat approach as a meta-framework for modelling household decision making.

3.7 Throughout the coding of the model, efforts have been made to attempt to ensure that there are as few errors and defects in the code as possible. This has been done by means of unit testing during coding, i.e. all methods have been tested to explore outputs individually to ensure they do what they are expected to do. Secondly, the developer, as well as potential users, have been running the simulation system to explore anything that looks odd, and that the system produces accurate representations. In other words, whenever any unexpected results are reported or found, attempts have been made to verify whether this is a true representation of the conceptual model or whether it is the outcome of a software bug. Throughout development, numerous bugs have been removed, and hopefully, there are none left.

\section{State variables and scales}

3.8 The model has been developed in interaction with potential users through the mapping of a set of interventions to increase the penetration of energy efficient products within a community. By mapping out potential interventions we have identified three types of agents to represent in the model as per Table 1. State variables are shown in Table2 2 to 5 . In addition to the agents described in Table 1, technologies are described representing energy-efficient products, and their alternatives. Therefore, there are two types of technologies for which the attributes are shown in Table 3 


\begin{tabular}{ll}
\hline Agent type & Role \\
\hline Household & Residents make decisions about whether to adopt an energy-efficient product. \\
Sales agent & $\begin{array}{l}\text { Sales agents may sell energy-efficient products, sometimes instigated through subsi- } \\
\text { dies. Sales-agents are assumed to primarily focus on maximising profits. }\end{array}$ \\
Information agents & $\begin{array}{l}\text { Information agents are those who provide recommendations to households on } \\
\text { whether to purchase an energy efficient products. These include retailers, state gov- } \\
\text { ernment, tradespeople, builders and media sources such as TV home improvement } \\
\text { programs and online forums Podkalicka 2018, Office of Environment and Heritage } \\
\text { NSW } 2014 \mathrm{~b} \text { a). }\end{array}$ \\
\hline
\end{tabular}

Table 1: Agent types. 


\begin{tabular}{|c|c|}
\hline Household variables & Description \\
\hline ID & An integer \\
\hline Dwelling type & $\begin{array}{l}\text { Detached house, Apartment / Unit / } \\
\text { Townhouse, Semi-detached or Terrace, } \\
\text { or Other. }\end{array}$ \\
\hline Household type & $\begin{array}{l}\text { Type of household, as per household ty- } \\
\text { pology. }\end{array}$ \\
\hline Location & $\begin{array}{l}\text { Coordinates on the map, representing a } \\
\text { physical location. }\end{array}$ \\
\hline
\end{tabular}

Personality A normalised value between 0 and 1

Financial vulnerabil- A 'financial vulnerability' score, which is ity

\section{Preferences}

Peers

Information source For each of the information sources, a profile

Technology owner- A zero or a one to indicate ownership. ship

Decision profile (dynamically evaluated in the simulation) as per the Consumat theory Jager \& Janssen 2012. normalised to a value between 0 and 1 .

A set of eight numbers between 0 and 1 , normalised so that the total score adds up to 1. Weights associated with each of the performance criteria. A number of peers (i.e. a list of their IDs) Describing the household social network. Initialised based on a specified social network. value 0 or 1 .

Plus another number to indicate the age (in years) of the associated product.

\section{Comments}

A unique number to represent the agent User-specified to reflect knowledge or data describing the target geographical area.

Currently randomly assigned. However, if the geographical locations of households are known, this can easily be added as a household variable and mapped in the GIS component in the user interface.

Responses to questions in a household survey that reflect personality are used to calculate a 'personality' score.

Based on the household survey, i.e. responses to questions that reflect financial vulnerability are used to calculate.

Based on the household survey, i.e. responses to questions that reflect preferences.

This is static as it would otherwise be computationally too expensive to run the simulations and a static network is considered an adequate approximation.

This denotes which of the information sources the household agent seeks recommendations from. Based on responses in the household survey.

Ownership of an energy efficient product (denoted by 1), or a non-energy efficient product (denoted by 0 ). Also, the age of the product. Ownership is dynamically updated and initialised based on surveys or expert opinion. The age of the technology is assigned based on a probability distribution, as per an input file.

As per Consumat theory Jager \& Janssen 2012. Assigned dynamically in the model on the basis of evaluated satisfaction and uncertainty. The fulfilment of three satisfaction criteria.

Dynamically determined based on inconsistency in criteria fulfilment.

As per Equation 1

My-performance, i.e. a value between 0 and 1.

Social needs satisfaction, i.e. a value between 0

Local-adoption-rate and 1. As per Equation 2

The adoption rate of the energy efficient product within their friends' network. Updated regularly.

Table 2: State variables of households, i.e. each household has values on these attributes. 
3.9 In Table 3 , the relative performance of the technologies is specified by the user within input files. The input files describe how the performance factors change over time. These can be estimated based on literature, survey and/or expert opinion. The performance values are normalised values between 0 and 1, where 0 is considered 'completely inferior to the alternative' and 1 is considered 'completely superior to the alternative'. The sum of the performance values for the two types of products add up to 1. If for example at a certain point in time, the upfront cost of the Energy Efficient (EE) technology is $\$ 100$ and the upfront cost of the OLD technology is $\$ 50$ then the Non-Energy Efficient (referred to as OLD) technology performs twice as well as the EE technology. Converted to performance attribute values, this translates to a value of $\sim 0.67$ for the OLD technology compared to $\sim 0.33$ for the EE technology. A subsidy for EE that would reduce the price from $\$ 100$ to $\$ 75$ would change the performance value for the EE product to 0.4 and the performance value for the OLD product to 0.6. Currently, the model only describes the choice between two types of technologies (EE: energy efficient, and OLD: not energy efficient). The state variables of technologies related to a large extent to the performance factors of the technologies, i.e. issues that have been identified as important within a literature review (Moglia et al.|2017). 


\begin{tabular}{|c|c|}
\hline State variable & Description \\
\hline Price & $\begin{array}{l}\text { People tend to be influenced by monetary considera- } \\
\text { tions which in turn are influenced by socio-economic } \\
\text { factors (Hall et al. 2013). The upfront price of a prod- } \\
\text { uct is particularly important because energy efficient } \\
\text { technologies tend to come at a higher initial cost and } \\
\text { access to capital can be an important limiting factor } \\
\text { in the adoption process (Wilson et al. 2015). }\end{array}$ \\
\hline \multicolumn{2}{|l|}{ Return on investment } \\
\hline \multicolumn{2}{|l|}{ Ongoing cost } \\
\hline Aesthetics & 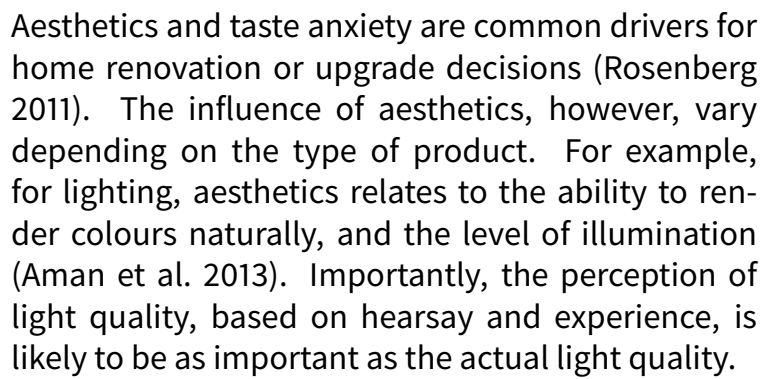 \\
\hline Comfort & $\begin{array}{l}\text { Some energy efficient products are associated with } \\
\text { greater reported home comfort, especially if this } \\
\text { comfort can come with less guilt about using energy } \\
\text { and emitting greenhouse gases Chua et al.2013, Wil- } \\
\text { son et al. 2015. }\end{array}$ \\
\hline Resale value & $\begin{array}{l}\text { Energy efficient products may make the property } \\
\text { more attractive and thus are sometimes believed to } \\
\text { create higher resale values (Noonan et al. 2013). }\end{array}$ \\
\hline \multirow[t]{3}{*}{ Electricity use } & $\begin{array}{l}\text { Not everyone is motivated by energy savings and en- } \\
\text { vironmental benefits, but some certainly are and this } \\
\text { is seen as a function of environmental attitudes and }\end{array}$ \\
\hline & awareness (Hall et al.2013; Liu et al. 2013, Newton \& \\
\hline & Meyer|2013) \\
\hline Environment - other & $\begin{array}{l}\text { There are also other environmental impacts of prod- } \\
\text { ucts beyond greenhouse gas emissions, for exam- } \\
\text { ple, some lighting types emit levels of mercury }(\mathrm{Hg}) \\
\text { which have been banned in some countries, but the } \\
\text { sale of these persist in other locations (Aman et al. } \\
2013 \text {. }\end{array}$ \\
\hline Proportion of energy use & $\begin{array}{l}\text { This represents on average how much of a house- } \\
\text { hold's energy is being used by the particular prod- } \\
\text { uct's end-use category. This information can be } \\
\text { sourced from government websites or industry } \\
\text { sources (Platinum Electricians 2018). }\end{array}$ \\
\hline Technology efficiency & $\begin{array}{l}\text { This represents the proportional reduction of the } \\
\text { household energy use (within the end-user category) } \\
\text { based on adopting the energy-efficient variety. This } \\
\text { information can be sourced from government web- } \\
\text { sites or industry sources. }\end{array}$ \\
\hline Probability of "end-of-life" (EOL) as a function of age & $\begin{array}{l}\text { This is the probability of a product being at the end of } \\
\text { its productive life as a function of age in years. Differ- } \\
\text { ent technologies have different ageing patterns and } \\
\text { expected productive lives so this is specified for each } \\
\text { product type. This can be established based on ex- } \\
\text { pert opinion or informed by manufacturers' specifi- } \\
\text { cations etc. }\end{array}$ \\
\hline
\end{tabular}

Table 3: State variables of technologies 


\begin{tabular}{|c|c|c|}
\hline State variable & Description & Change \\
\hline Records of sales success and failure & $\begin{array}{l}\text { Track record in selling energy efficient products to allow } \\
\text { appropriate updating of the sales strategy. }\end{array}$ & Dynamic \\
\hline Expenses & $\begin{array}{l}\text { Expenses when purchasing and selling the energy effi- } \\
\text { cient product. }\end{array}$ & Dynamic \\
\hline Income & $\begin{array}{l}\text { Income associated with selling the energy efficient prod- } \\
\text { uct. }\end{array}$ & Dynamic \\
\hline Sales price & $\begin{array}{l}\text { The price at which the sales agent will sell the product. } \\
\text { This is updated based on the sales track record and esti- } \\
\text { mated return on investments. }\end{array}$ & Dynamic \\
\hline Administration cost factor & $\begin{array}{l}\text { The cost of administering the subsidy scheme. In the } \\
\text { context of New South Wales, this is the Energy Savings } \\
\text { Scheme (NSW Government|2018). Default value: } 1.05 \text { i.e. } \\
5 \% \text { on top of price estimated. }\end{array}$ & Static \\
\hline Cost of sales attempt & $\begin{array}{l}\text { The cost of an attempt to sell the product, regardless of } \\
\text { success. Static Purchasing discount The discount that the } \\
\text { sales agent could receive when purchasing the product. } \\
\text { Default value: } 0.15 \text {, i.e. } 15 \% \text { discount. Based on expert } \\
\text { opinion. }\end{array}$ & Static \\
\hline
\end{tabular}

Table 4: State variables of sales agents

\begin{tabular}{ll}
\hline State variable & Description \\
\hline Preferences & $\begin{array}{l}\text { A set of normalised weights (between } 0 \text { and } 1 \text { and adding up to 1) associated with the } \\
\text { performance criteria: price, aesthetics, electricity use, environmental issues, comfort, } \\
\text { the return on investments, ongoing costs, and impact on resale value. These are based } \\
\text { on expert opinion or survey and are entered by the user through an input file. }\end{array}$ \\
$\begin{array}{l}\text { Evaluated dynamically on request based on a choice model equation to estimate the } \\
\text { probability of recommending the EE product. }\end{array}$ \\
\hline
\end{tabular}

Table 5: State variables of information agents

\section{Process overview and scheduling}

3.10 The process of the model is conceptually described in Figure 1 


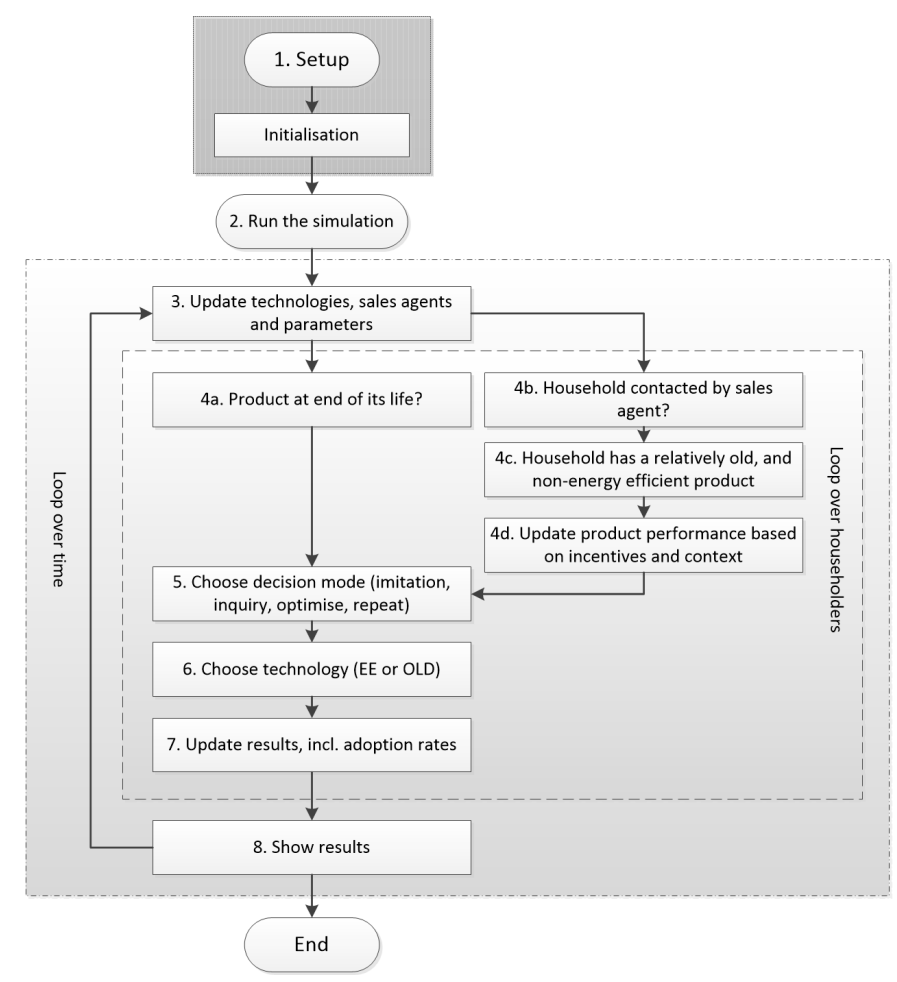

Figure 1: Conceptual description of simulation process (adapted from Sopha et al.2013.

\section{Household agent decision making}

3.11 Modelling the household decision making is a two-step process. Firstly, the household is only considering purchasing a product in certain circumstances. Secondly, once the household considers purchasing a product, the approach for choosing which product to buy is determined by the Consumat theory. For the first part of this process, there are two decision trigger points, as shown in Table 6 .

\begin{tabular}{ll}
\hline Decision trigger points & Description \\
\hline Product at end-of-Life & $\begin{array}{l}\text { When the product (i.e. hot water system etc.) has reached the end of its } \\
\text { life, the consumer will consider purchasing a replacement. } \\
\text { Bneang approached by sales-agent } \\
\text { of the population and attempt to sell an energy efficient product. This } \\
\text { does not always trigger a decision point, as described below. }\end{array}$ \\
\hline
\end{tabular}

Table 6: State variables of information agents

3.12 Once a household agent initiates the decision making process, the process follows the Consumat theory which is based on social psychology whereby the mode of decision making hinges on two issues, i.e. firstly the level of satisfaction and secondly, the amount of uncertainty, i.e. the amount of cognitive effort required in making a decision. Depending on high and low needs satisfaction, and high and low uncertainty, the four modes of decision making are as follows. The level of needs satisfaction and the level of uncertainty when a household agent makes a decision is in turn based on three criteria, Existential Needs Satisfaction (see Equation 11, Social Needs Satisfaction (see Equation 2) and Primary Focus Satisfaction, i.e. whether the highest priority performance > 0.5 as this means that the option outranks the alternative (the performance values are normalised in order to add up to 1). These criteria are thought to be satisfied when the value is above 0.5 .

$$
\begin{gathered}
\text { Existential Needs Satisfaction (i) }=\left(\sum_{j=1 \text { to } 8} w_{i, j} \cdot p_{i, j}\right)+\text { Behaviour-Adjustment } \\
\text { Social Needs Satisfaction (i) }=\left(a_{i} \cdot u\right)+(1-u) \cdot\left(1-a_{i}\right)
\end{gathered}
$$


Behaviour-Adjustment $=$ Delta(hassle) + Delta(discount $)+$ Delta(free $)+$

$$
\text { Delta(word-of-mouth) + Delta(status-quo-bias) }
$$

3.13 Here,

- $i$ refers to household number $\mathrm{i}$,

- $w(i, j)$ refers to the preference weight of household i regarding performance factor $j$.The weights add up to 1.

- $p_{j}$ refers to the performance of the energy efficient product against factor $j$. This is a normalised number between 0 and 1 .

- $a_{i}$ refers to the personality value of household $\mathrm{i}$

- $u$ refers to the adoption rate of energy efficient products.

3.14 The behaviour adjustment factors and their values are further described in the supplementary materials. The choice of the decision mode is based on how many criteria are being fulfilled, which is an adaptation of the Consumat theory, as per Jager \& Janssen 2012. The Consumat meta-theory of decision making considers existential needs satisfaction and social needs satisfaction, as well as an evaluation of uncertainty in expected outcomes. After deliberation within the team, it was thought that it is beyond householders' consideration to consider uncertainty in statistical expectations, but within their capacity to consider inconsistency between social and existential needs satisfaction, and other criteria. We also wanted to consider a crowding out effect, where particular preference is given to the householder's most important issue. Therefore we consider that satisfaction and uncertainty are based on the overall weight of the three criteria, in the following manner: 1) no criterion fulfilled: unsatisfied and certain, 2) one criterion fulfilled: unsatisfied and uncertain, 3) two criteria fulfilled: satisfied and uncertain, 4) three criteria fulfilled: satisfied and certain. The decision modes are as follows.

- Repetition: Satisfied and certain. Repeating the behaviour of the past, i.e. if a household agent already has an EE product, the household agent will then also upgrade with an EE product, and vice versa.

- Imitation: Satisfied and uncertain. Copying the behaviour of a household within the social network. Only friends that are "satisfied" are considered. If the household has no satisfied friends, then the household will consider the adoption rate in the broader community, i.e. if the uptake of EE is $25 \%$ then the likelihood that a household will adopt EE is $25 \%$.

- Optimisation: Unsatisfied and certain. Choosing the product with the highest overall performance, i.e. the weighted sum of product performance and individual priority weights, plus behavioural factors.

- Inquiry: Unsatisfied and uncertain. Seek recommendations from the information sources that the household agent will consider (as per attributes in Table 22. A probability $p$ of adopting EE is calculated as the weight of recommendations for EE divided by the weight of recommendations for EE and OLD.

\section{Information agent decision making}

3.15 Information agents provide recommendations to households (i.e. 'you should buy an energy efficient product', etc.) when households are in the 'inquiry' decision mode. In the default model, there are nine types of information sources, i.e. family and friends, TV home improvement programs (based on expert opinion, two different types of shows are included due to their current dominant position in the Australian market, i.e. Grand Designs and The Block), retailers (two included), tradespeople, online forums, builders, government information sources; these are chosen and parameterised based on information in industry reports Office of Environment and Heritage NSW 2014b a and academic papers (Rosenberg 2011; Podkalicka 2018). To determine which recommendation to provide, information agents have the same type of attributes as households regarding prioritising different performance measures (see Table 5 on performance measures for each of the technology options to calculate the probability of recommending an EE product based on a discrete choice logit model:

$$
P(\text { recommendation }=E E)=\frac{e^{(k \cdot \mu)}}{e^{(k \cdot \mu)}+e^{(k \cdot(1-\mu)}}
$$


3.16 Here, $\mu$ is the weighted performance of the EE products, and where the weights are the information agents' priorities, as per Table 2 $k$ is a weighting factor which should ideally be fitted based on choice experiment data; however in the absence of this data the parameter has been set to 5 so that the equation reproduces what is considered realistic behaviour.

\section{Sales agent decision making}

3.17 Sales agents represent actors who will contact households directly to attempt to get them to upgrade to an energy efficient type of product. In the context of the Energy Savings Scheme in New South Wales, these may be what are called the 'aggregators' who create energy saving certificates on behalf of clients, and who thus can claim the financial reward of doing so (each certificate can be claimed at a price which is adjusted on an ongoing basis). However, sales agents do not necessarily need a subsidy from the government, but may also simply be able to create a financially viable business by purchasing discounted products and having an acceptable level of success in their sales activities.

3.18 In each time step (as per Figure 1), sales agents contact a certain number of households and attempt to sell an energy efficient product. In the model, a household will make a decision based on the following rules:

- If the household does not already own an energy efficient product, and if the existing non-energy-efficient product is past its half-life (here defined as when half of all products have reached the end of their useful life), the household will consider purchasing an energy efficient product (i.e. initiate a decision-making process). This rule is based on the acknowledgement that householders may sometimes, in some circumstances, consider replacing a product even when it isn't broken, for lifestyle reasons or due to a perceived opportunity to "get a good deal".

- In this context, the household will only initiate a decision making process for purchasing an EE product if they believe that a good deal can be made that will soon be unavailable, i.e. if it is sold either at or below current market price. Once the decision-making process has been initiated, all the usual performance issues will be considered as per household preferences (see Table 2 and 3 .

- Then, if the household escalates to the decision making process, the eventual decision will be on the basis of the Optimise decision mode, i.e. on the basis of existential needs satisfaction (Equation 1, but with adjustment for the price provided by the sales agent, and with the usual behaviour-adjustments.

3.19 Furthermore, in each time step, each sales agent will update their attributes and decision rules on the basis of the assumption that they will act as financial rational actors and maximise their profits (which is consistent with indications from qualitative research in the project, from medium-sized to large businesses; but not appropriate for smaller companies):

- Calculating the success rate, i.e. the number of successful sales calls divided by the total number of sales calls.

- Calculating the return on investments by dividing the profit with costs.

- Adjusting the outreach (i.e. the number of sales calls made in each time step), on the basis of:

- If more than 3 times target return on investments, then grow this number by $25 \%$

- If more than 1.5 times target return investments, then grow this number by $10 \%$

- If more than target return on investments, then grow this number by $1 \%$

- If making a loss, then halve this number

Adjusting the sales price on the basis of an expected success rate and on the basis of ensuring a target return on investments (by calculating the expenses 'per sale' and choosing a price at the $25 \%$ mark between the estimated cost and the market price of the system). 


\section{Design concepts}

3.20 Key aspects of the NED are mapped out and described, as per Kiesling et al. (2012), in Table 7. This table has a number of concepts and notions that are not described in detail here but which are described in more detail in the earlier part of the paper.

\begin{tabular}{|c|c|}
\hline Model features & NED design feature \\
\hline Method for agent adaptation & $\begin{array}{l}\text { Household agents make decisions using decision rules, } \\
\text { as per the social psychology approach based on the Con- } \\
\text { sumat theory (Jager \& Janssen 2012, Janssen \& Jager } \\
\text { 1999, Jager et al. 2001). }\end{array}$ \\
\hline Emergence & $\begin{array}{l}\text { The Consumat model allows for decision rules, two of } \\
\text { which enable a degree of emergent behaviour due to in- } \\
\text { teraction with other agents. These two decision rules are } \\
\text { imitation and inquiry. }\end{array}$ \\
\hline Fitness & $\begin{array}{l}\text { Households calculate the fitness of adopting a technol- } \\
\text { ogy based on their perceived capacity to fulfil social and } \\
\text { existential needs. }\end{array}$ \\
\hline Interaction & $\begin{array}{l}\text { Households interact with each other through imitation, } \\
\text { inquiry and social comparison. Social needs evaluations } \\
\text { are dependent on the behaviour of other households. } \\
\text { In addition, households are influenced by information } \\
\text { agents in the inquiry decision mode and sales agents trig- } \\
\text { ger household decision points. }\end{array}$ \\
\hline Level of social influence (micro, meso or macro) & $\begin{array}{l}\text { There is an influence at the micro-scale (via connected } \\
\text { friends), mesoscale (via aggregate measures within } \\
\text { groups of friends), and macro-scale (via aggregate mea- } \\
\text { sures at the community level). Imitation occurs at the } \\
\text { micro-level. The user can provide input through a 'slider' } \\
\text { to decide to what extent social comparison occurs at the } \\
\text { mesoscale or the macro-scale. The default is set to the } \\
\text { mesoscale. }\end{array}$ \\
\hline Social network typology & $\begin{array}{l}\text { There is a social network connecting household agents. } \\
\text { The user can choose between friends' network based on } \\
\text { a small world network, random network, or a spatially } \\
\text { based network (i.e. neighbours). The social networks are } \\
\text { based on synthetic data generated using various algo- } \\
\text { rithms such as the: small-world networks (Watts \& Stro- } \\
\text { gatz 1998 or scale-free networks (Barabási 2002). }\end{array}$ \\
\hline Consumer heterogeneity and collectives & $\begin{array}{l}\text { A household survey was used to describe heterogeneity } \\
\text { in 1) priorities; 2) level of financial vulnerability; } 3 \text { ) types } \\
\text { of the households as per typology; 4) preferred informa- } \\
\text { tion sources used. }\end{array}$ \\
\hline
\end{tabular}

Table 7: Model features in NED

\section{Setup and initialisation}

3.21 The model is being set up in a process that involves 1) user inputs to choose parameters and model settings, 2) reading input files, 3) creating agents to represent households, information agents, and sales agents, 4) creating a social network between households, and 5) creating technologies and assign their attribute values as per input files.

3.22 The number of household agents of different dwelling types and household types (with categories as per Table 2 are defined in an input file, typically representing census data of the target area. An example of the information structure is shown in the supplementary materials.

3.23 When a household agent is created, it receives its attributes copied from the survey responses, currently a database of 954 responses (Office of Environment and Heritage NSW 2014a). Rather than providing the raw 
survey data, this file represents the result of statistical analysis of the survey data. Python scripts were used to process the initial survey responses into a format that is appropriate as an input file for the simulator. The assignment of attributes is carried out as per Figure2. There are also input files to specify the attributes of the information and sales agents (examples provided in the supplementary materials).

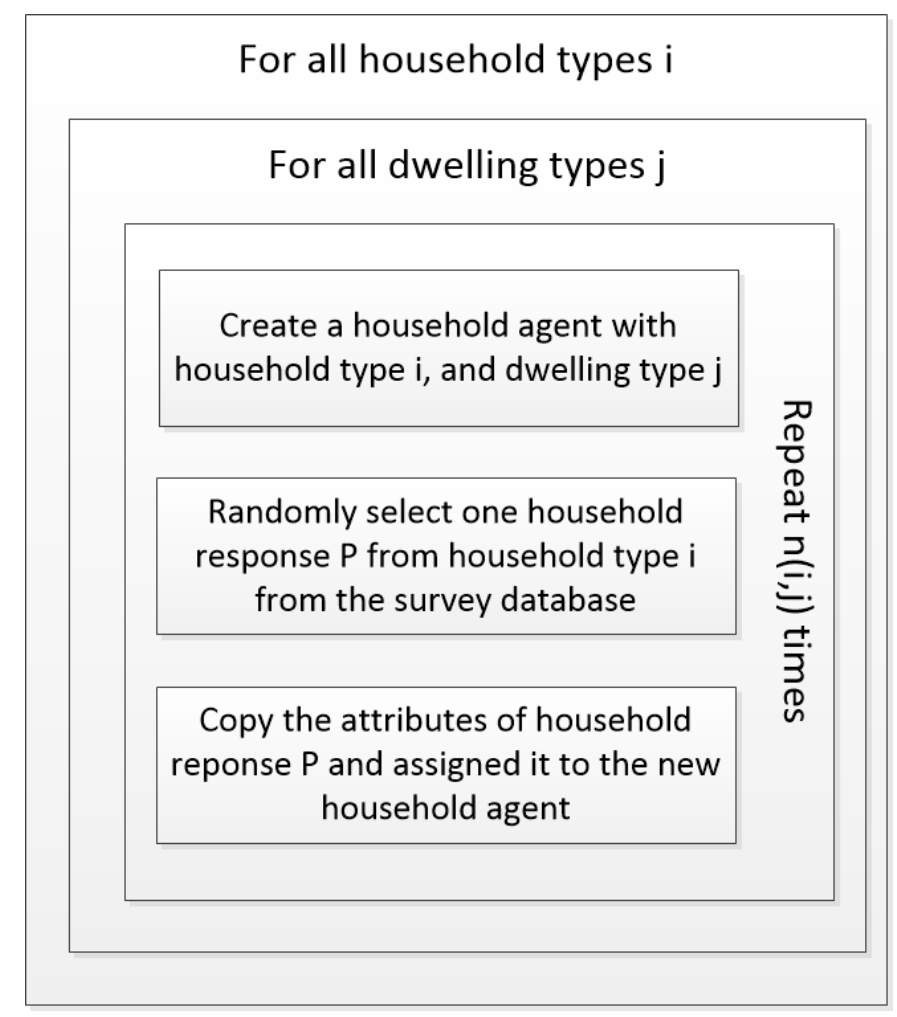

Figure 2: Initialisation of household agents. $n(i, j)$ is the number of households of household type $i$, and dwelling type $j$ as per input file.

\section{Input}

3.24 A key driver for the model dynamics is the technology performance which is specified through input files. Due to limitations in space required and to illustrate the approach, we only focus on hot water systems here. The values on technology performance of hot water systems are shown in Table 8 . 


\begin{tabular}{|c|c|c|c|}
\hline Performance metric & Start & End & Data source \\
\hline Price & 0.18 & 0.40 & $\begin{array}{l}\text { Consumer websites in Australia put the price of a solar hot } \\
\text { water system in the range of } \$ 3,000-\$ 7,000 \text { fully installed } \\
\text { Choice|2017); whilst an alternative system would cost } \$ 450 \\
-\$ 1,800 \text { (Australian Hot Water 2017). }\end{array}$ \\
\hline Aesthetics & 0.50 & 0.50 & $\begin{array}{l}\text { It is assumed that there are no discernible differences be- } \\
\text { tween systems in this respect. }\end{array}$ \\
\hline Electricity use & 0.71 & 0.90 & $\begin{array}{l}\text { Numbers on annual electricity use from Moore et al. } 2017 \text {. } \\
15,260 \mathrm{MJ} / \mathrm{y} \text { for an electric storage system; and } 6,104 \mathrm{MJ} / \mathrm{y} \text { for } \\
\text { a solar electric system. It is assumed that these numbers will } \\
\text { improve over the time frame. }\end{array}$ \\
\hline Environmental issues (other) & 0.50 & 0.50 & $\begin{array}{l}\text { It is assumed that there are no discernible differences be } \\
\text { tween systems in this respect, as there have been no such } \\
\text { findings reported. }\end{array}$ \\
\hline Comfort & 0.55 & 0.65 & $\begin{array}{l}\text { Expert opinion. To be estimated using surveys in the future. } \\
\text { This represents the notion that using hot water without the } \\
\text { added guilt of spending much money or overly polluting the } \\
\text { environment makes for a more comfortable home. }\end{array}$ \\
\hline Long-term cost & 0.58 & 0.80 & $\begin{array}{l}\text { Calculated based on initial price and electricity use plus } \\
\$ 0.25 \text { per kWh (Australian prices) and the cost over a } 12 \text {-year } \\
\text { time frame; as } 12 \text { years is an approximate expected life of a } \\
\text { hot water system. }\end{array}$ \\
\hline Ongoing cost & 0.71 & 0.90 & Assumed to be perfectly aligned with electricity use. \\
\hline Impact on resale value & 0.52 & 0.55 & Expert opinion. To be estimated using surveys in the future. \\
\hline
\end{tabular}

Table 8: Technology performance input

3.25 Furthermore, based on conversations with experts and review of the literature, we adopt a set of assumptions that relate to hot water systems and to the interventions to attempt to increase adoption rates; as shown in Table 9 . 


\begin{tabular}{|c|c|}
\hline Input setting & Explanation \\
\hline Initial adoption rate, i.e. $p$-start & $\begin{array}{l}\text { The adoption rate at the start of the simulation } \\
\text { is } 21 \% \text { based on data from Beal et al. (2012). It } \\
\text { is noted that this is data from Queensland rather } \\
\text { than New South Wales (i.e. a similar jurisdiction). }\end{array}$ \\
\hline Urgency of replacement & $\begin{array}{l}\text { It is assumed that when a hot water system breaks } \\
\text { down, due to the urgency of the situation, house- } \\
\text { holds will not analyse the problem in detail; and } \\
\text { thus we set the uncertainty as high which will trig- } \\
\text { ger the inquiry or imitate modes of decision mak- } \\
\text { ing. The only time, for the case of hot water sys- } \\
\text { tems, that a decision will be made through care- } \\
\text { ful evaluation (optimise mode) is when being ap- } \\
\text { proached by a sales agent. }\end{array}$ \\
\hline Promoting solar hot water systems amongst plumbers & $\begin{array}{l}\text { Working with plumbers to achieve a greater rate of } \\
\text { recommendations of solar hot water systems, thus } \\
\text { for this scenario, we put the tradespersons' priori- } \\
\text { ties to be: } 30 \% \text { price, } 50 \% \text { electricity use, and } 20 \% \\
\text { comfort. }\end{array}$ \\
\hline Subsidy & $\begin{array}{l}\text { Providing a } 20 \% \text { subsidy on all purchases of solar } \\
\text { hot water systems. }\end{array}$ \\
\hline Energy savings scheme certificates & $\begin{array}{l}\text { Making a subsidy available to sales agents via en- } \\
\text { ergy savings certificates (say at } 20 \text {, or } 30 \text { per certifi- } \\
\text { cate). The idea is that this prompts sales agents to } \\
\text { be proactive in their attempts to sell solar hot wa- } \\
\text { ter systems to the community. }\end{array}$ \\
\hline Social network & $\begin{array}{l}\text { For the purposes of this paper, a small world social } \\
\text { network is employed, generated using the Klein- } \\
\text { berg model with a clustering component set to 2, } \\
\text { as is considered to be optimal Easley \& Kleinberg } \\
2010 \text {. }\end{array}$ \\
\hline Awareness & $\begin{array}{l}\text { It is assumed that everyone knows about solar hot } \\
\text { water systems as an option so the Awarness Impact } \\
\text { is set to } 0 \text { (meaning that awareness is } 100 \% \text { from } \\
\text { the start). }\end{array}$ \\
\hline Time frame of simulation & $\begin{array}{l}\text { We have chosen to simulate the adoption of tech- } \\
\text { nology over the time frame of } 2017-2047 \text {. We } \\
\text { recognise that this means that much will change } \\
\text { during this time frame and that it is unlikely that } \\
\text { things will stay as they are described in the model. } \\
\text { However, we also like a longer time frame in order } \\
\text { to highlight the long term benefits of decisions be- } \\
\text { ing made now. }\end{array}$ \\
\hline
\end{tabular}

Table 9: Input settings

\section{Sub-models}

3.26 An important aspect of the model is to calculate reductions in carbon emissions, and therefore the carbon accounting component estimates reductions in carbon emissions. For example for the solar hot water systems, the assumptions are shown in Table 10 


\begin{tabular}{|c|c|}
\hline Parameter & Explanation \\
\hline Proportion of household energy use & $\begin{array}{l}\text { Hot water is assumed to account for } 21 \% \text { of the household energy use } \\
\text { (NSW Government 2016). }\end{array}$ \\
\hline Reduction in energy use & $\begin{array}{l}\text { A solar hot water system is assumed to reduce energy use for produc- } \\
\text { ing hot water by } 60 \% \text { (Moore et al. } 2017 \text { ). }\end{array}$ \\
\hline Household energy use per year & $\begin{array}{l}\text { An average household in New South Wales, Australia, is assumed to } \\
\text { use approximately 5,920kWh per year (Acil Allen Consulting 2015). }\end{array}$ \\
\hline Emissions factor & $\begin{array}{l}\text { For New South Wales the emissions factor is set to } 0.86 \mathrm{~kg} \mathrm{CO}_{2}- \\
e / \mathrm{kWh} \text { (Australian Government 2014). }\end{array}$ \\
\hline Emissions factor gradient & $\begin{array}{l}\text { It is assumed that with the gradual installation of renewable energy } \\
\text { and other cleaner energy sources, the emissions factor will continu- } \\
\text { ally drop at a rate of } 0.01 \text { per annum. }\end{array}$ \\
\hline
\end{tabular}

Table 10: Carbon accounting parameters

\section{Scenario Results}

4.1 To illustrate the use of the model, we will report on the following explorations:

1. Testing the model for stability: does the model have significant amounts of randomness embedded or does it produce similar results every time?

2. Sensitivity analysis to policy interventions: what interventions are more efficient in increasing adoption rates?

\section{Testing the stability and validity of the model}

4.2 Running the model multiple times with a baseline scenario, i.e. with no intervention, helps to explore whether the model provides repeatable results. As there is a range of stochastic aspects of the model, it would seem likely that different simulation runs would provide significantly different results but this does not seem to be the case, as illustrated by Figure 3

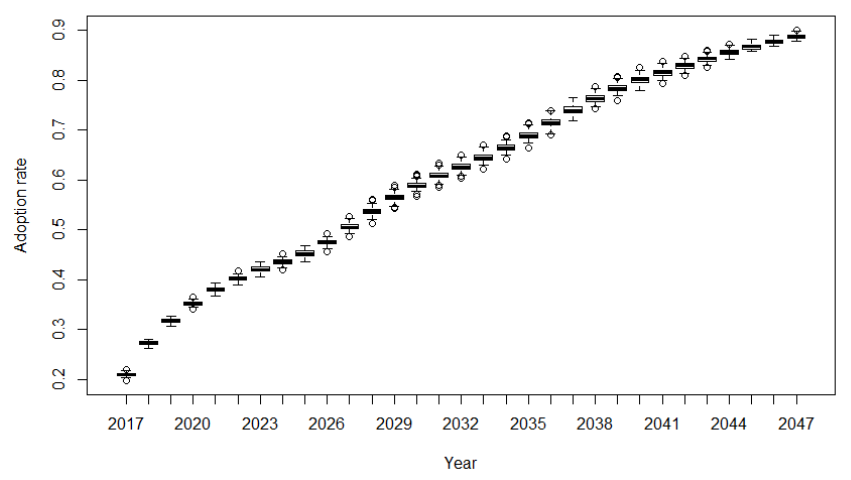

Figure 3: Baseline scenario as Box-Whiskers Plot based on 50 simulation runs. For each year, the plot indicates the median adoption rate with a line and then the $25 \%$ percentile, $75 \%$ percentile, in a box, as well as minimum and maximum values.

4.3 The average adoption rates of 50 simulation runs each for four different types of social network, are shown in Figure 5 which shows only limited variability between runs. There are some systematic differences depending on the underlying social network structure however with slightly higher rates of adoption in the scale-free social networks. We believe this relatively small difference in results arising from variable social network typology is 
due to adoption rates being fairly homogenous across the population. Other observations from the simulations are:

- Sales agent never gets activated in this baseline scenario because the return on investment never gets above the critical threshold as the certificate price is $\$ 0$ so the sales agent struggles to generate profit.

- Adoption rate curve seems to follow what will have to be assumed the 'middle part' of an S-curve (standard in innovation diffusion), which is consistent with starting at a starting adoption rate of $21 \%$ and not reaching a plateau during the simulation time frame.

4.4 It is unfortunate that there is no accessible longitudinal data on uptake of solar hot water systems available in Australia in order to validate the model against. In terms of validation, only limited comparison with historical data is possible but a paper by Ferrari et al. (2012) with data on sales of solar hot water systems shows that the $35 \%$ of hot water systems sold in 2010 in New South Wales were solar hot water systems. This is consistent with the linear trend in the sales rate (i.e. the proportion of new products being solar hot water systems) extracted from the model when the trend in the sales rate is extended back in time (see Figure 6). This is promising, considering none of the parameters in the model were calibrated to fit with historical data. Explorations of the parameter space is warranted, however full sensitivity analysis is beyond the scope of this paper due to the complexity of the model. Gotts \& Polhill 2017) suggest a suitable approach for complex models such as these, i.e. 1) enter parameter values which seem to reasonably fit with empirical data, 2) systematically vary parameters that seem likely to most influence results. The sensitivity analysis can easily be supported in the NetLogo BehaviourSpace tool, and through the relatively intuitive user interface, as is illustrated with the sensitivity analysis for the $\mathrm{k}$ weighting factor in Equation 4 (representing approximately the inertia in getting information sources to recommend energy efficient technologies). See Figure 4 for the result of this sensitivity analysis.

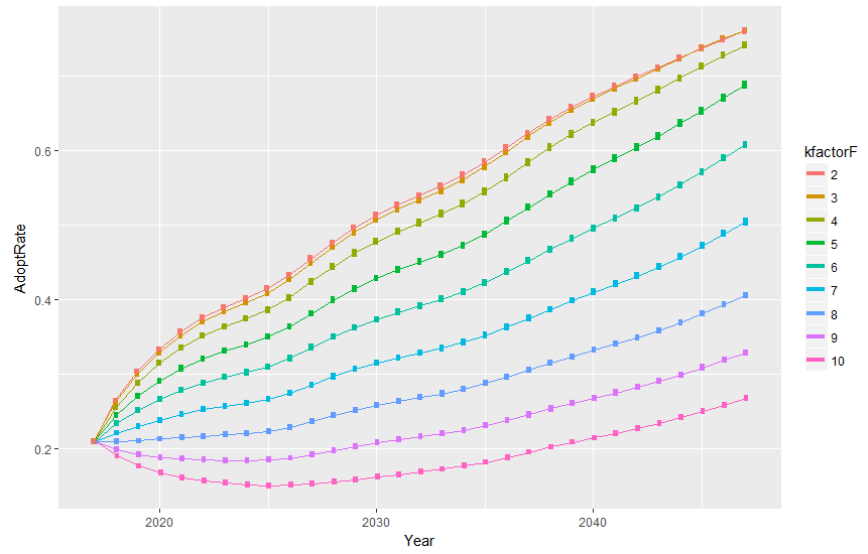

Figure 4: Sensitivity analysis showing the result of 50 simulation runs for each $k$ weighting factor setting between 2 and 10. This factor represents the inertia in information sources recommendations of energy efficient technology. There are error bars present but not displaying clearly due to the small amount of variation between runs. 


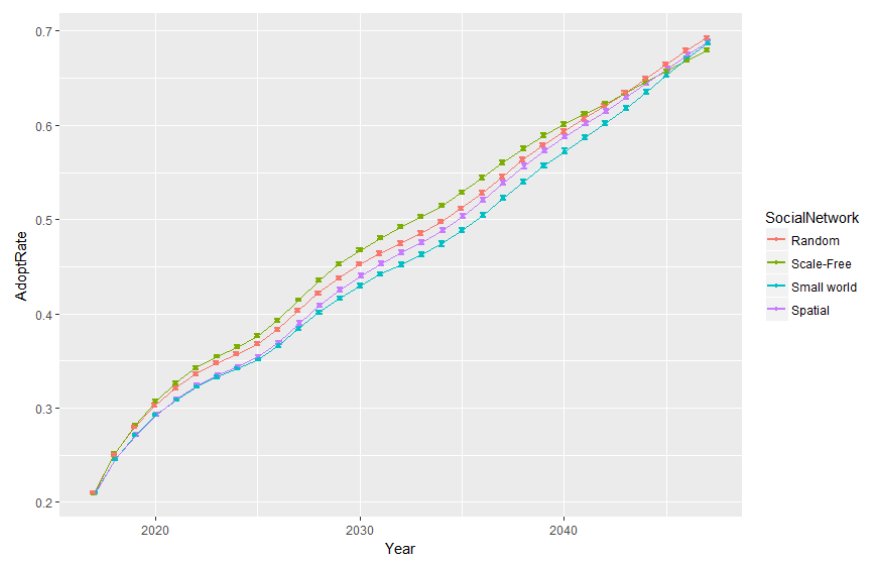

Figure 5: Adoption rates from 50 simulation runs for each social network setting, with the baseline case of no interventions in the case of using a Small-world, Scale-free, Spatial and Random social network. X-axis: years. Y-axis: Adoption rates of solar hot water systems, as a proportion of all hot water systems, including confidence intervals around each data point (i.e. the width of the confidence intervals are +/- 1.96 standard errors).

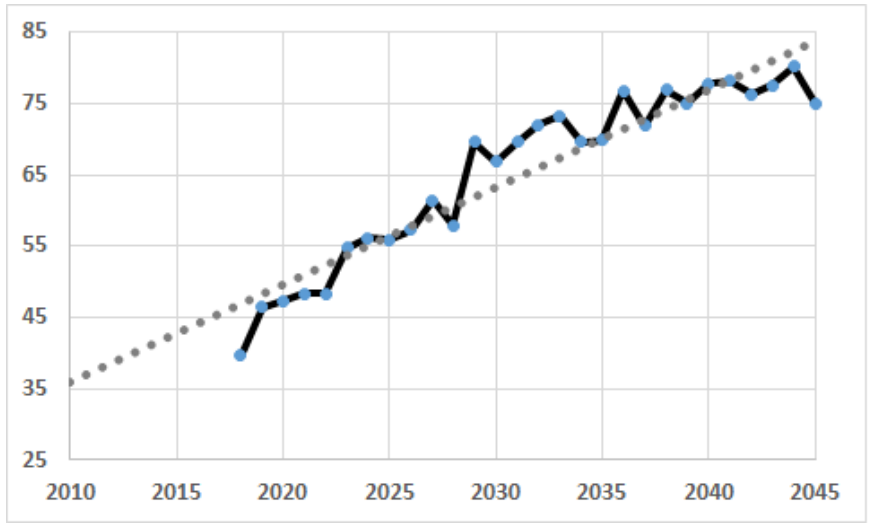

Figure 6: Sales rate (proportion of all sales being solar hot water) as a function of time. X-axis: years; and Y-axis: the proportion of hot water systems being solar hot water systems. A trend line has also been added to illustrate projected sales rates, going backwards in time. Note that there is only limited variation between runs using this model as illustrated in Figures 4 and 5

\section{Evaluating interventions}

4.5 The types of interventions that the model could explore include: 1) activating sales agents to attempt to sell more energy efficient products to the community, 2) influencing retailers and other key actors such as tradespeople to recommend the adoption of energy-efficient products, and 3) providing direct subsidy to community members for purchasing energy efficient products through cheap loans and/or subsidies. Specifically, to illustrate the use of the model, here we describe a couple of interventions to promote the adoption of hot water systems, including:

- The Energy Savings Scheme (NSW Government 2018) whereby so-called aggregators apply for energy savings certificates after installing, improving or replacing energy savings equipment. They may choose to proactively target householders to increase sales of energy efficient products and they may also choose to use some of the energy savings certificates to reduce the price of products. We explore three settings on the energy savings certificates, i.e. $\$ 0, \$ 20$, and $\$ 30$.

- Working with plumbers to increase the rate of recommendations of solar hot water systems. The plumber is often contacted by householders when a hot water system breaks down. In this scenario, the recommendations of plumbers are based on a choice model of hypothesized priorities as per the supplementary materials. 
- Providing a $20 \%$ subsidy directly to households when they choose whether to purchase an energy efficient product, regardless how or where they purchase it.

4.6 These options have been explored individually as well as in combination as per Figure 7 and Table 11. It is clear that in this case, the monetary incentive through the Energy Savings Scheme is less efficient than the approach of influencing the recommendations of plumbers, and also less efficient than the $20 \%$ subsidy. Whether working with plumbers is more cost effective than providing a subsidy is unknown due to the difficulty in estimating the cost of influencing plumber recommendations.

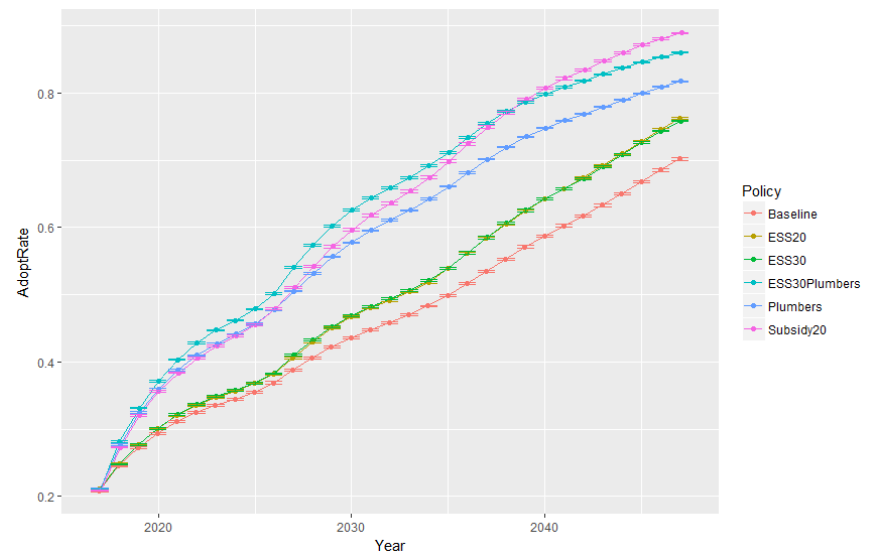

Figure 7: Exploring the result of a set of possible interventions. X-axis: years. Y-axis: Adoption rates of solar hot water systems, as a proportion of all hot water systems. The plot has been generated in $\mathrm{R}$ based in simulation results (30 simulation runs for each policy setting), showing the standard errors as bars.

\begin{tabular}{|c|c|c|c|c|}
\hline & $\begin{array}{l}\mathrm{CO}_{2}-\mathrm{e} \text { re- } \\
\text { duction per } \\
\text { householda }^{\mathrm{a}}\end{array}$ & $\begin{array}{l}\text { Cost per hh per } \\
\text { year (C) }\end{array}$ & $\begin{array}{l}\text { Adoption rate } \\
2047(\%)\end{array}$ & $\begin{array}{l}\text { Additional re- } \\
\text { duction }(\Delta)^{\mathbf{b}}\end{array}$ \\
\hline Baseline, i.e. no intervention & 3.81 & $\$ 0$ & 68.6 & - \\
\hline ESS - \$20 & 4.39 & $\$ 19$ & 75.5 & 0.58 \\
\hline ESS - $\$ 30$ & 4.54 & $\$ 29$ & 76.5 & 0.73 \\
\hline Working with plumbers & 5.93 & Unknown & 81.5 & 2.12 \\
\hline $20 \%$ subsidy & 6.32 & $\$ 17$ & 88.9 & 2.51 \\
\hline
\end{tabular}

Table 11: Summary of scenario results. Notes. ${ }^{\text {a }}$ : the unit is tonnes of $\mathrm{CO}_{2}-e$ over a 30 year time period. ${ }^{\text {b: }}$ Calculated as the reduction per household above the baseline scenario.

\section{Reflections}

5.1 The scenario analysis demonstrates that running model simulations provide insights beyond what is accessible with human cognitive functions. The model is able to explore where in the supply chain it is most cost-effective to incentivise decision making in order to promote the adoption of energy-efficient products.

5.2 Furthermore, as is the strength of many ABMs when embedding socio-psychological models, the NED model is able to explore less tangible issues like common human biases in decision making, for example, the status quo bias, and the benefits of making adoption less of a hassle.

5.3 In terms of specific results, the scenario analysis has shown that in the case of solar hot water systems and with of the described population, it is more cost effective to provide a subsidy to households rather than to incentivise sales agents via energy savings certificates. This is despite the fact that sales agents generate decision points that otherwise would not occur. This is somewhat counter-intuitive because otherwise subsidies only get activated when a product reaches the end of its life. Thus without marketing activities from sales agents, the maximum rate of the upgrade is dependent on the ageing of products and is limited. 
5.4 To validate this finding, regarding the effectiveness of providing a subsidy to households vs. incentivising sales agents, it will be necessary to collect better data on the model parameter, the 'discount-effect', which relates to the behavioural biases of mental accounting (Thaler 1985.

5.5 Nonetheless, it seems likely it is more cost-effective to promote plumbers to recommend solar hot water systems. This shows the importance of providing the right information at the right time to households. In the case of solar hot water systems, plumbers engage with householders and have the opportunity to provide them with the right information at the right time.

5.6 At a higher level, the model explorations also show that when modelling adoption processes, it is critical to understand the process of adoption, which can vary significantly depending on the type of intervention into the system. Embedding insights from behavioural science as much as possible allows for fine-tuning some key parameters in the delivery of interventions.

5.7 Regarding the viability of the modelling approach, we believe it has potential to support plans to increase resource efficiency in society and thus can help improve sustainability outcomes. The approach is adaptable to many types of situations but will require some effort to tweak and update the models.

5.8 To adapt the model to new contexts and interventions, the main task is in collecting the appropriate data, including surveys of households and key actors. Other actors that need to be surveyed are sales agents, information agents and supply chain actors. To illustrate the extent of data collection required, in a subsequent project where an adaptation of model is being developed on the topic of water conservation, the team has developed a standardised survey (requiring a couple of days to a week to adjust to new context next time), and in that context we surveyed 500 households which should suffice in most situations. The data collection for other agents, such as plumbers, supply chain actors or retailers, may be based on knowledge elicitation in a one-day workshop setting for each category.

5.9 For those unfamiliar with ABM, the coding of the model is relatively straightforward, yet requires familiarity with the model itself, as well as some training in Agent-Based Modelling.

5.10 The modelling capability described in this paper has here been applied to residential energy efficiency but adjustments of the model are being built to allow the analysis of interventions to increase household water conservation as well as shifting suburban commuter travel modes to low carbon alternatives.

\section{Conclusions}

6.1 This paper provides the description of an ABM that represents the adoption processes of energy-efficient products. The computational engine has two sides of it, i.e. the Consumat meta-model of human behaviour which is based on social psychology theory, as well as the mapping of the processes of adoption. By applying the model to the case of solar hot water systems, a number of insights were generated, including the need to influence households at the right time and place, i.e. when the existing hot water system breaks down. The best approach for doing so is by influencing plumbers to recommend the installation of solar hot water systems. This can be achieved by providing them with training or educational materials. A particularly important insight is that it is not only residents that need to be incentivised; there can be an ecosystem of types of agents, and it is necessary to identify the most effective intervention point in the system. In the case of solar hot water systems, this intervention point appears to be the plumbers. In the future, this model will also be applied to the context of water conservation and low carbon transport.

\section{Appendix}

Pseudo-code to describe the NED model. The total code is several thousand lines, but here is an extract of some key methods.

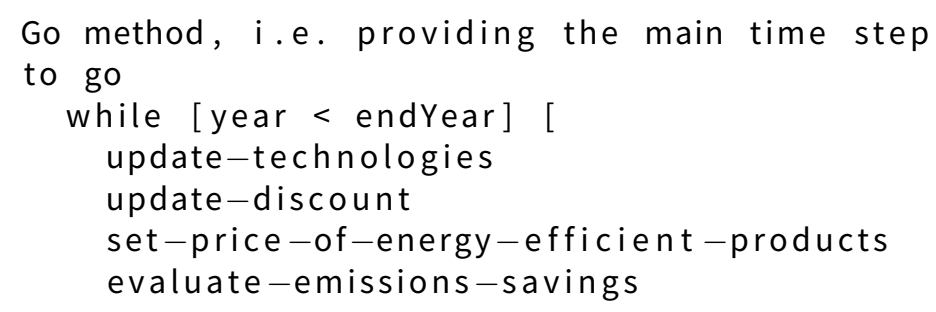




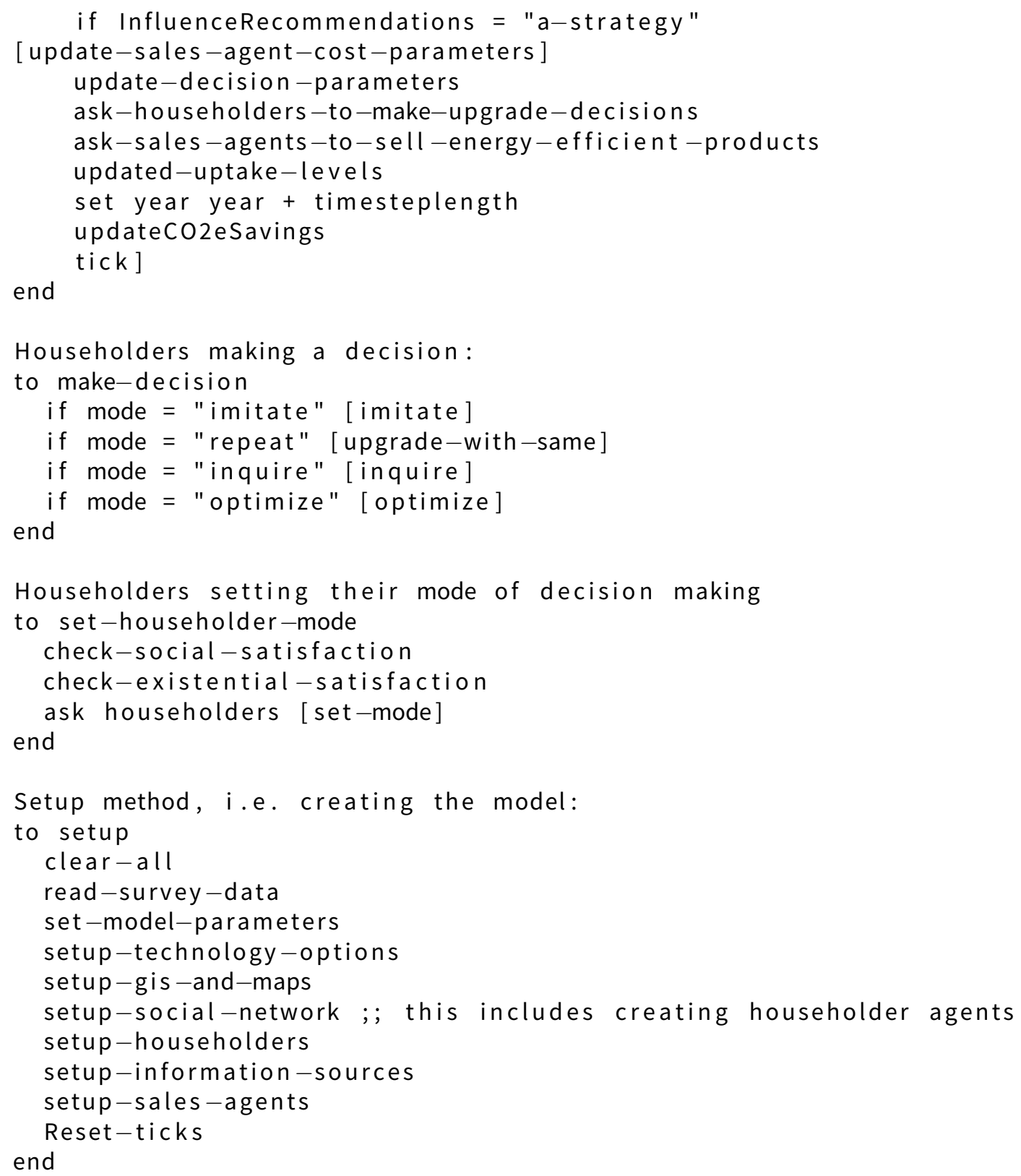

\section{References}

Acil Allen Consulting (2015). Electricity bill benchmarks for residential customers. A report to the Australian energy regulator

Aman, M., Jasmon, G., Mokhlis, H. \& Bakar, A. (2013). Analysis of the performance of domestic lighting lamps. Energy Policy, 52, 482-500

Australian Government (2013). Energy | your home [online]. Available: http://www.yourhome.gov.au/ energy [Accessed 1st September 2016. Archived by WebCite at http://www . webcitation. org/6wBBx1crL 2016

Australian Government (2014). National greenhouse accounts factors. Australian Government.

Australian Hot Water (2017). 6 steps to calculating the price of a hot water system [online]. Available: https:// australianhotwater.com.au/6-steps-calculating-price-hot-water-system/[Accessed 4th December. Archived by WebCite at http://www . webcitation .org/6wBAaqZH1 2017]

Barabási, A.-L. (2002). Linked: The New Science of Networks. New York, NY: Perseus 
Bass, F. M. (1969). A new product growth for model consumer durables. Management Science, 15(5), 215-227

Bass, F. M. (2004). Comments on "A new product growth for model consumer durables the bass model". Management Science, 50 , 1833-1840

Beal, C. D., Bertone, E. \& Stewart, R. A. (2012). Evaluating the energy and carbon reductions resulting from resource-efficient household stock. Energy and Buildings, 55, 422-432

Benartzi, S., Beshears, J., Milkman, K. L., Sunstein, C. R., Thaler, R. H., Shankar, M., Tucker-Ray, W., Congdon, W. J. \& Galing, S. (2017). Should governments invest more in nudging? Psychological Science, 28(8), 10411055

Boschetti, F., Grigg, N. J. \& Enting, I. (2011). Modelling = conditional prediction. Ecological Complexity, 8(1), 86-91

Brook, B. W. \& Barnosky, A. D. (2013). Quaternary extinctions and their link to climate change. In Saving a Million Species: Extinction Risk from Climate Change, (pp. 179-198). Berlin/Heidelberg: Springer

Choice (2017). Prices on solar hot water systems [online]. Available: https://www.choice.com.au/ home-improvement/energy-saving/solar/buying-guides/solar-hot-water-systems [Accessed 4th December. Archived by WebCite at http://www.webcitation.org/6wBBahPOf 2017]

Chua, K. J., Chou, S. K., Yang, W. M. \& Yan, J. (2013). Achieving better energy-efficient air conditioning - A review of technologies and strategies. Applied Energy, 104, 87-104

Conijn, J. G., Bindraban, P. S., Schröder, J. J. \& Jongschaap, R. E. E. (2018). Can our global food system meet food demand within planetary boundaries? Agriculture, Ecosystems \& Environment, 251, 244-256

Di Maria, C., Ferreira, S. \& Lazarova, E. (2010). Shedding light on the light bulb puzzle: The role of attitudes and perceptions in the adoption of energy efficient light bulbs. Scottish Journal of Political Economy, 57(1), 48-67

Drummond, P. \& Ekins, P. (2016). Reducing $\mathrm{CO}_{2}$ emissions from residential energy use. Building Research \& Information, 44(5-6), 585-603

Easley, D. \& Kleinberg, J. (2010). Networks, Crowds, and Markets: Reasoning about a Highly Connected World. Cambridge: Cambridge University Press

Estiri, H. (2015). Household energy consumption and housing choice in the US residential sector. Housing Policy Debate, 26(1), 231-250

Ferrari, D., Guthrie, K., Ott, S. \& Thomson, R. (2012). Learning from interventions aimed at mainstreaming solar hot water in the Australian market. Energy Procedia, 30, 1401-1410

Frederiks, E. R., Stenner, K. \& Hobman, E. V. (2015). Household energy use: Applying behavioural economics to understand consumer decision-making and behaviour. Renewable and Sustainable Energy Reviews, 41, 1385-1394

Geller, H., Harrington, P., Rosenfeld, A. H., Tanishima, S. \& Unander, F. (2006). Polices for increasing energy efficiency: Thirty years of experience in OECD countries. Energy Policy, 34(5), 556-573

Gilbert, N. \& Troitzsch, K. (2000). Simulation for the Social Scientist. Buckingham, PA: Open University Press

Gotts, N. M. \& Polhill, J. G. (2017). Experiments with a model of domestic energy demand. Journal of Artificial Societies and Social Simulation, 20(3), 11

Grimm, V., Berger, U., Bastiansen, F., Eliassen, S., Ginot, V., Giske, J., Goss-Custard, J., Grand, T., Heinz, S. K., Huse, G., Huth, A., Jepsen, J. U., JÃÿrgensen, C., Mooij, W. M., MÃijller, B., PeâĂŹer, G., Piou, C., Railsback, S. F., Robbins, A. M., Robbins, M. M., Rossmanith, E., RÃijger, N., Strand, E., Souissi, S., Stillman, R. A., VabÃ̈̈, R., Visser, U. \& DeAngelis, D. L. (2006). A standard protocol for describing individual-based and agent-based models. Ecological Modelling, 198(1âĂş2), 115 - 126

Grimm, V., Berger, U., DeAngelis, D. L., Polhill, J. G., Giske, J. \& Railsback, S. F. (2010). The ODD protocol: A review and first update. Ecological Modelling, 221(23), 2760-2768

Gruber, H. \& Verboven, F. (2001). The diffusion of mobile telecommunications services in the European Union. European Economic Review, 45(3), 577-588 
Günther, M., Stummer, C., Wakolbinger, L. M. \& Wildpaner, M. (2011). An agent-based simulation approach for the new product diffusion of a novel biomass fuel. Journal of the Operational Research Society, 62(1), 12-20

Gupta, R. \& Jain, K. (2012). Diffusion of mobile telephony in India: An empirical study. Technological Forecasting and Social Change, 79(4), 709-715

Hall, N., Romanach, L., Cook, S. \& Meikle, S. (2013). Increasing energy-saving actions in low income households to achieve sustainability. Sustainability, 5(11), 4561-4577

Hetherington, J., Roetzel, A. \& Fuller, R. (2015). The impact of occupant behaviour on residential greenhouse gas emissions reduction. Journal of Green Building, 10(4), 127-140

Hicks, A. L. \& Theis, T. L. (2014). An agent based approach to the potential for rebound resulting from evolution of residential lighting technologies. International Journal of Life Cycle Assessment, 19(2), 370-376

Higgins, A., Foliente, G. \& McNamara, C. (2011). Modelling intervention options to reduce GHG emissions in housing stock - A diffusion approach. Technological Forecasting and Social Change, 78(4), 621-634

Higgins, A., Paevere, P., Gardner, J. \& Quezada, G. (2012). Combining choice modelling and multi-criteria analysis for technology diffusion: An application to the uptake of electric vehicles. Technological Forecasting and Social Change, 79(8), 1399-1412

Higgins, A., Syme, M., McGregor, J., Marquez, L. \& Seo, S. (2014). Forecasting uptake of retrofit packages in office building stock under government incentives. Energy Policy, 65, 501-511

Höhne, N., Blum, H., Fuglestvedt, J., Skeie, R. B., Kurosawa, A., Hu, G., Lowe, J., Gohar, L., Matthews, B., Nioac De Salles, A. C. \& Ellermann, C. (2011). Contributions of individual countries' emissions to climate change and their uncertainty. Climatic Change, 106(3), 359-391

Hovmand, P. S. (2013). Group model building and community-based system dynamics process. In P. S. Hovmand (Ed.), Community Based System Dynamics, (pp. 17-30). New York, NY: Springer

Jager, W. \& Janssen, M. (2012). An updated conceptual framework for integrated modeling of human decision making: The consumat ii. In Complexity in the Real World ECCS 2012 - from policy intelligence to intelligent policy, (pp. 1-18)

Jager, W., Janssen, M. A. \& Viek, C. (2001). Experimentation with household dynamics: The Consumat approach. International Journal of Sustainable Development, 4(1), 90-100

Janssen, M. \& Jager, W. (1999). An integrated approach to simulating behavioural processes: A case study of the lock-in of consumption patterns. Journal of Artificial Societies and Social Simulation, 2(2), 2

Khan, N. \& Abas, N. (2011). Comparative study of energy saving light sources. Renewable and Sustainable Energy Reviews, 15(1), 296-309

Kiesling, E., Günther, M., Stummer, C. \& Wakolbinger, L. M. (2012). Agent-based simulation of innovation diffusion: A review. Central European Journal of Operations Research, 20(2), 183-230

Liu, J.-L., Chang, P.-I. \& Den, S.-J. (2013). Consumer willingness to pay for energy conservation: a comparison between revealed and stated preference method. Procedia Environmental Sciences, 17, 620-629

Macal, C. M. (2016). Everything you need to know about agent-based modelling and simulation. Journal of Simulation, $10(2)$, 144-156

Macal, C. M. \& North, M. J. (2005). Tutorial on agent-based modeling and simulation. In Proceedings of the 2005 Winter Simulation Conference, (pp. 2-15). IEEE

Mao, C., Zou, M., Liu, Y., Xue, W. \& Li, M. (2015). Comparison of agent-based modeling and equation-based modeling for transportation behavioral studies. In Proceedings of the 15th COTA International Conference of Transportation Professionals, (pp. 3610-3625)

Marquez, L., Higgins, A., Sendaba, B. \& McGregor, J. (2013). Understanding influence networks using an agentbased model of technology adoption for commercial building retrofits. ISORAP 2013

Moglia, M., Cook, S. \& McGregor, J. (2017). A review of agent-based modelling of technology diffusion with special reference to residential energy efficiency. Sustainable Cities and Society, 31, 173-182 
Moglia, M., Perez, P. \& Burn, S. (2010). Modelling an urban water system on the edge of chaos. Environmental Modelling \& Software, 25(12), 1528-1538

Moore, A., Urmee, T., Bahri, P., Rezvani, S. \& Baverstock, G. (2017). Life cycle assessment of domestic hot water systems in Australia. Renewable Energy, 103, 187-196

Newton, P. \& Meyer, D. (2013). Exploring the attitudes-action gap in household resource consumption: Does "environmental lifestyle" segmentation align with consumer behaviour? Sustainability, 5(3), 1211-1233

Noonan, D. S., Hsieh, L.-H. C. \& Matisoff, D. (2013). Spatial effects in energy-efficient residential HVAC technology adoption. Environment and Behavior, 45(4), 476-503

NSW Government (2016). Draft plan to save NSW energy and money. Sidney, Australia

NSW Government (2018). Energy savings scheme [online]. Available: https://www.ess.nsw.gov.au/Home [Accessed 3rd January. Archived by WebCite at http://www . webcitation . org/6wBBn8WgZ 2018]

OECD (2014). Greening household behaviour: A review for policy makers. OECD Publishing

Office of Environment and Heritage NSW (2014a). Sustainable households survey of homeowners for the NSW Office of Environment and Heritage. Sydney, Australia

Office of Environment and Heritage NSW (2014b). Sustainable households: Survey of tradespeople. Sydney, Australia

Perez, P. \& Batten, D. F. (2006). Complex Science for a Complex World: Exploring Human Ecosystems with Agents. Canberra: ANU E Press

Platinum Electricians (2018). How much power is needed to run an average home? [online]. Available: https: //www.platinumelectricians.com.au/blog/power-needed-run-average-home/[Accessed 3rd January. Archived by WebCite at http: //www . webcitation .org/6wBDTqsVu 2018]

Podkalicka, A. (2018). Actor, intermediary, and context: Locating media as part of consumption and home renovation practice. Journal of Communication Research and Practice, (p. in press)

Polhill, G. \& Gotts, N. (2017). How precise are the specifications of a psychological theory? Comparing implementations of Lindenberg and Steg's Goal-Framing Theory of everyday pro-environmental behaviour. In Advances in Social Simulation 2015, (pp. 341-354). Berlin/Heidelberg: Springer

Rai, V. \& Henry, A. D. (2016). Agent-based modelling of consumer energy choices. Nature Climate Change, 6(6), 556

Rockström, J., Steffen, W., Noone, K., Persson, A., Chapin III, F. S., Lambin, E., Lenton, T. M., Scheffer, M., Folke, C., Schellnhuber, H. J. et al. (2009). Planetary boundaries: Exploring the safe operating space for humanity. Ecology and Society, 14(2), 32

Rogers, E. (1962). Diffusion of Innovations. New York, NY: Simon and Schuster

Rosenberg, B. C. (2011). Home improvement: Domestic taste, DIY, and the property market. Home Cultures, 8(1), 5-23

Sopha, B. M., Klöckner, C. A. \& Febrianti, D. (2017). Using agent-based modeling to explore policy options supporting adoption of natural gas vehicles in Indonesia. Journal of Environmental Psychology, 52, 149-165

Sopha, B. M., Klöckner, C. A. \& Hertwich, E. G. (2013). Adoption and diffusion of heating systems in Norway: Coupling agent-based modeling with empirical research. Environmental Innovation and Societal Transitions, $8,42-61$

Swan, L. G. \& Ugursal, V. I. (2009). Modeling of end-use energy consumption in the residential sector: A review of modeling techniques. Renewable and Sustainable Energy Reviews, 13(8), 1819-1835

Thaler, R. (1985). Mental accounting and consumer choice. Marketing Science, 4(3), 199-214

Thuiller, W., Lavorel, S., Araújo, M. B., Sykes, M. T. \& Prentice, I. C. (2005). Climate change threats to plant diversity in Europe. Proceedings of the National Academy of Sciences of the United States of America, 102(23), $8245-8250$ 
Tran, M. (2012). Agent-behaviour and network influence on energy innovation diffusion. Communications in Nonlinear Science and Numerical Simulation, 17(9), 3682-3695

Van Vliet, O., De Vries, B., Faaij, A., Turkenburg, W. \& Jager, W. (2010). Multi-agent simulation of adoption of alternative fuels. Transportation Research Part D: Transport and Environment, 15(6), 326-342

Vennix, J. (1996). Group Model Building. New York, NY: Wiley

Watts, D. J. \& Strogatz, S. H. (1998). Collective dynamics of 'small-world' networks. Nature, 393(6684), 440-442

Wilensky, U. (1999). Netlogo. Center for Connected Learning and Computer-Based Modeling, Northwestern University

Wilson, C., Crane, L. \& Chryssochoidis, G. (2015). Why do homeowners renovate energy efficiently? Contrasting perspectives and implications for policy. Energy Research \& Social Science, 7, 12-22

Zalasiewicz, J. A. N., Williams, M., Steffen, W. \& Crutzen, P. (2010). The new world of the Anthropocene. Environmental Science and Technology, 44, 2228-2231

Zhang, T., Gensler, S. \& Garcia, R. (2011). A study of the diffusion of alternative fuel vehicles: An agent-based modeling approach. Journal of Product Innovation Management, 28(2), 152-168 